\title{
PEP Does Not Dispense with but Implements Task-Set Reconfiguration. Can It Handle Phenomena More Diagnostic of Endogenous Control?
}

\author{
Stephen Monsell and Ian McLaren \\ University of Exeter, GB \\ Corresponding author: Stephen Monsell (S.Monsell@exeter.ac.uk)
}

Invited commentary on Schmidt, Liefooghe, and De Houwer (2020) An episodic model of task switching effects: erasing the homunculus from memory. Journal of Cognition.

Keywords: Cognitive Control; Executive functions; Task-switching

In their article, Schmidt, Liefooghe, and De Houwer (2020) - henceforward "SL\&DH":

(1) focus on how immediate repetition of cues, stimuli and responses in task-cuing experiments modulate RT and error rate, inflating (they say) the "true" cost of a task switch;

(2) propose a computational account - PEP - in terms of retrieval of episodic traces in which stimulus, cue and response representations have been bound to tasks initially by instruction, then by recent trials;

(3) argue that the PEP model is sufficient to explain the phenomena observed in task- switching experiments phenomena without appeal to control via a task-set reconfiguration (TSR) control process.

Deconstruction of quasi-homuncular theoretical constructs of executive control in terms of an "army of idiots" - simple well-specified mechanisms, such as memory retrieval, that we think we understand - is a goal we share with SL\&DH (Monsell \& Driver, 2000; Verbruggen, McLaren \& Chambers, 2014). We commend their explicit modelling of the influence of immediate repetitions on the switch cost, but comment here, in turn, on these three components of their argument, of which the third is the most contentious.

\section{Effect of immediate repetitions and the switch cost}

It has been known for a long time that task-switch costs are modulated by immediate repetition of cues (Logan \& Bundesen, 2003), and responses (Rogers \& Monsell, 1995) and that immediate repetition of a stimulus enables abbreviated processing on task-repeat trials (Bertelson, 1961, Kornblum, 1973), while inducing interference when the task changes. SL\&DH model data from a study by Schmidt and Liefooghe (2016), which carefully assessed how all three kinds of repetition modulated the task-switch cost, finding the effects to be substantial. However, the assertion on the basis of just one study that, in the absence of all three kinds of immediate repetition, "true" switch costs are relatively trivial is surely premature. ${ }^{1}$ As SL\&DH acknowledge, substantial switch costs have been observed in numerous experiments where cue repetitions have been prevented, and/or large stimulus or response sets have been used so that repetitions occured, if at all, at long lags.

${ }^{1}$ Cf. Logan and Bundesen's (2003) initial claim that most of the task-switch cost in cueing experiments could be accounted for by a confound of task- and cue-repetition; although cue repetition is a significant factor, robust switch costs have generally been found when cue repetition is controlled or prevented (e.g. Monsell \& Mizon, 2006). 


\section{Explanation of immediate repetition effects}

Associative "binding" or "integration" in episodic traces is certainly a candidate mechanism to explain effects of repetition. The model fits render it plausible. But there are other accounts of immediate repetition effects, notably priming, as in the Schneider and Logan (2005) explanation of cue repetition effects as priming of cue encoding due to residual activation. We add the terminological note that even if one hypothesizes that an effect results from binding or feature integration biases, one should not slip into calling these effects "binding" or "integration" effects: this muddles description and interpretation. ${ }^{2}$

Perhaps because their focus is on effects of immediate repetition, SL\&DH seem to make no distinction between transient binding in event files in working memory (e.g. Hommel, 1998 ) and long term learning of associations, as in the association of task-sets to stimuli proposed by Waszak, Hommel and Allport (2003). And the attribution of associative effects to episodic instance representations rather than more abstractive associative learning seems - as in other domains of cognition - an ideological rather than an evidencedetermined choice.

\section{Does the PEP model dispense with TSR?}

SL\&DH's radical claim is that the PEP model provides a simpler, mechanistic, alternative to a TSR account of task-cuing and -switching. In thus reaching for Occam's razor, we think SL\&DH over-reach. First, the focus of their modelling is on modulations of the switch cost by repetition effects and the effect of response congruence. The empirical phenomena that primarily motivate a TSR account are mentioned only as an afterthought, with the hope that the PEP model may be able to handle them. Second, the TSR account which SL\&DH reject ("it seems clear that the PEP model is not consistent with the task-set reconfiguration account") is a straw man. Indeed, as far as we can see, their PEP model implements an appropriately formulated TSR account.

The observation most suggestive of an active TSR process is that motivated participants can achieve a substantial reduction of switch cost ("RISC") if given foreknowledge (e.g. by a task cue) of the task to be required when the stimulus appears, and time to prepare. No less important is the asymptotic "residual cost" seen after a long preparation interval: this implies limits to what can be achieved by anticipatory TSR.

In the PEP model, goal nodes, their connections, and episodic traces created initially by instruction, represent the task-sets in play; task-sets are selected by activation of the goal nodes. SL\&DH think this "overstates [the] function" of the goal nodes, because "all these nodes do is retrieve the viable decision options it is considering". But, once the network is set up and instructed by seeding episodic traces, that is all the task-set control needed for their paradigm. Cues activate the task nodes, which then modulate the response activation produced by the stimulus (to a degree biased by recent episodic bindings) in an explicitly two-step process: task-set selection, then response selection. The first step is the reconfiguration process. This may be contrasted with Schneider and Logan's (2005) one-step compound stimulus model, which really does dispense with control of task set (albeit, we think, inappropriately; see Forrest, Monsell \& McLaren, 2014).

SL\&DH think their PEP model is inconsistent with a TSR account because they assume that TSR must be a discrete stage rather than a dynamic process, and requires a "switch detector" to initiate task preparation on switch trials, with no preparation on repeat trials. Neither is a necessary property of the broad class of TSR accounts. While some early variants did construe TSR as a discrete stage (or two stages, e.g. Rogers \& Monsell, 1995), or an all-or-none accomplishment (De Jong, 2000), in more recent discussions we (e.g. Monsell, 2015, 2017; Monsell \& Mizon, 2006) and others acknowledge the possibility of TSR being an incremental dynamic process (as in connectionist characterisations of control of task-set by context, e.g. Miller and Cohen, 2001; Gilbert and Shallice, 2002) admitting of degrees of accomplishment. Research on the "posterior positivity" believed to be an ERP correlate of anticipatory TSR has highlighted trial to trial variability in the degree of preparation achieved (Lavric, Mizon \& Monsell, 2008; Karayanidis et at, 2011). Nor is a "switch detector" essential to the TSR account (though some authors have assumed or implied one.) Strictly speaking, in TSR accounts "reconfiguration" is not the control process but its result (on switch trials). The "act of control" activation of the task-set triggered by the cue (or other foreknowledge) - may well happen on all trials, as in the PEP account. Reconfiguring of task-set links and parameters is the result achieved (or at least attempted) by activating the cued task-set on switch trials; preparatory (re)activation of the current task-set may indeed

\footnotetext{
${ }^{2}$ Cf. the labelling of instances of interference (with performance) as cases of inhibition when the latter is only one possible mechanism for the former (MacLeod et al., 2003). For the same reason, in task-switching we should not call n-2 repetition benefits "backward inhibition".
} 
occur on repeat trials as well, reinforcing the existing configuration (see Steinhauser, Maier and Ernst, 2017, for ERP evidence).

As far as we are aware, no recent theorist attributes switch costs solely to TSR; most accounts are "hybrid" (Monsell, 2003) in the sense that the switch cost, the RISC function, and response congruence effects, are the outcomes of, essentially, a competition between the control process and what it has to overcome, namely carry over of the previous tasks' parameters (orientation of attention, S-R rules, etc) or inhibition thereof (Allport, Styles \& Hsieh, 1994), and/or associative reactivation by the stimulus of task-set parameters (Waszak, Hommel \& Allport, 2013). (For review see Kiesel et al., 2010; Monsell, 2015; Vandierendonck, Liefooghe, \& Verbruggen, 2010). The switch cost indexes not the duration of TSR but its efficacy. The rate at which the switch cost reduces as the preparation interval increases (the slope of the RISC function) is as close as we can get to timing a TSR process using RT. In their Discussion, SL\&DH speculate that the PEP model may explain the effect of preparation interval by assuming early activation of the goal nodes. This is anticipatory TSR! It remains to be seen whether a parameterisation of the PEP model which can simulate the RISC effect will also simulate the residual cost.

An apparent virtue of the PEP account is that, once the network is set up and episodic traces formed, performance is driven automatically by the cue and stimulus on each trial, biased by the recent past, without endogenous control exterior to the network. Indeed, there is no distinction between endogenous and exogenous control; all the task-set control needed is exercised via activation of goal nodes by cues. As a consequence, the PEP model seems ill-equipped to deal with the variable and volitional quality of task-set control. Participants do not really have to proactively prepare in most experiments with a long preparation interval, and a RISC effect is sometimes not seen under conditions that we may suspect demotivate advance preparation (e.g. Altmann, 2004; Roger \& Monsell, 1995). Switch costs exhibit substantial variability both over trials and over participants in a way most easily understood as variability in TSR effort, not just noise. The timing of the ERP posterior positivity is sensitive to when the stimulus is expected, not simply timelocked to the cue or previous response (Karayanidis et al., 2003, 2014). Participants appear to adjust how fully or often they prepare for a change of task as a function of the probability (Monsell \& Mizon, 2006; Mayr, Kuhns \& Rieter, 2013) or predictability (Monsell, Sumner \& Waters, 2003) of a task-switch in the immediate future. In short, on top of the control already embedded in the PEP model, it would appear to require a superordinate level of monitoring and adjustment of the exercise of that control (as in the Brown, Reynolds \& Braver, 2007, network).

Moreover, in experiments very like Schmidt and Liefooghe (2006), but with only 4 stimuli, Forrest et al. (2014) found that participants could be induced to adopt, and sometimes discovered without explicit instruction, Schneider and Logan's (2005) one-step strategy of retrieving responses to cue-stimulus compounds. This manifested in a pattern of performance (minimal switch costs, no RISC effect, and large congruence effects modulated by practice) very different from the standard task-switching pattern obtained in participants given standard task-cuing instructions and identical cue-stimulus trial sequences. A PEP network might well be able to simulate this alternative pattern, but would still need an account of how two such different patterns of performance could emerge with identical sequences of cues and stimuli.

Hence, far from "erasing" task-set reconfiguration, SL\&DH's PEP model implements a minimal version of it, but needs to be tested for its ability to handle the RISC function, including the residual cost, and will need additional mechanisms to capture phenomena suggestive of strategic modulation of control and process architecture.

\section{Competing Interests}

The authors have no competing interests to declare.

\section{References}

Allport, D. A., Styles, E. A., \& Hsieh, S. (1994). Shifting intentional set: Exploring the dynamic control of tasks. In C. Umiltà \& M. Moscovitch (Eds.), Attention and performance XV: Conscious and nonconscious information processing (pp. 421-452). Cambridge, MA: MIT Press.

Altmann, E. M. (2004). The preparation effect in task switching: Carryover of SOA. Memory \& Cognition, 32, 153-163. DOI: https://doi.org/10.3758/BF03195828

Bertelson, P. (1961). Sequential redundancy and speed in a serial two-choice responding task. Quarterly Journal of Experimental Psychology, 13, 90-102. DOI: https://doi.org/10.1080/1747021610 8416478 
Brown, J. W., Reynolds, J. R., \& Braver, T. S. (2007). A computational model of fractionated conflictcontrol mechanisms in task-switching. Cognitive Psychology, 55, 37-85. DOI: https://doi.org/10.1016/j. cogpsych.2006.09.005

De Jong, R. (2000). An intention-activation account of residual switch costs. In S. Monsell \& J. Driver (Eds.), Control of cognitive processes: Attention and Performance XVIII (pp. 357-376). Cambridge, MA: MIT Press.

Forrest, C. L. D., Monsell, S., \& McLaren, I. P. L. (2014). Is performance in task-cuing experiments mediated by task set selection or associative compound retrieval? Journal of Experimental Psychology: Learning Memory and Cognition, 40, 1002-1024. DOI: https://doi.org/10.1037/a0035981

Gilbert, S. J., \& Shallice, T. (2002). Task switching: A PDP model. Cognitive Psychology, 44, 297-337. DOI: https://doi.org/10.1006/cogp.2001.0770

Hommel, B. (1998). Event files: Evidence for automatic integration of stimulus-response episodes. Visual Cognition, 5, 183-216. DOI: https://doi.org/10.1080/713756773

Karayanidis, F., Coltheart, M., Michie, P. T., \& Murphy, K. (2003). Electrophysiological correlates of anticipatory and poststimulus components of task switching. Psychophysiology, 40, 329-348. DOI: https://doi.org/10.1111/1469-8986.00037

Karayanidis, F., \& Jamadar, S. (2014). Event-related potentials reveal multiple components of proactive and reactive control in task-switching. In J. A. Grange \& G. Houghton (Eds.), Task switching and cognitive control. New York: Oxford University Press. DOI: https://doi.org/10.1093/acprof:os obl/9780199921959.003.0009

Karayanidis, F., Provost, A., Brown, S., Paton, B., \& Heathcote, A. (2011). Switch-specific and general preparation map onto different ERP components in a task-switching paradigm. Psychophysiology, 48, 559-568. DOI: https://doi.org/10.1111/j.1469-8986.2010.01115.x

Kiesel, A., Steinhauser, M., Wendt, M., Falkenstein, M., Jost, K., Philipp, A. M., \& Koch, I. (2010). Control and interference in task switching - A review. Psychological Bulletin, 136, 849-874. DOI: https://doi. org/10.1037/a0019842

Kornblum, S. (1973). Sequential effects in choice reaction time: A tutorial review. In S. Kornblum (Ed.), Attention and Performance IV (pp. 259-288). New York: Academic Press.

Lavric, A., Mizon, G. A., \& Monsell, S. (2008). Neurophysiological signature of effective anticipatory task-set control: A task-switching investigation. European Journal of Neuroscience, 28, 1016-1029. DOI: https://doi.org/10.1111/j.1460-9568.2008.06372.x

Logan, G., \& Bundesen, C. (2003). Clever homunculus: Is there an endogenous act of control in the explicit task-cuing procedure? Journal of Experimental Psychology: Human Perception and Performance, 29, 575-599. DOI: https://doi.org/10.1037/0096-1523.29.3.575

MacLeod, C., Dodd, M. D., Sheard, E. D., Wilson, D. E., \& Bibi, U. (2003). In opposition to inhibition. In B. H. Ross (Ed.), The Psychology of Learning and Motivation, 43, 163-214. Elsevier Science. DOI: https:// doi.org/10.1016/S0079-7421(03)01014-4

Mayr, U., Kuhns, D., \& Rieter, M. (2013). Eye movements reveal dynamics of task control. Journal of Experimental Psychology: General, 142, 489-509. DOI: https://doi.org/10.1037/a0029353

Miller, E. K., \& Cohen, J. (2001). An integrative theory of prefrontal cortex function, Annual Review of Neuroscience, 24, 167-202. DOI: https://doi.org/10.1146/annurev.neuro.24.1.167

Monsell, S. (2003). Task switching. Trends in Cognitive Sciences, 7, 134-140. DOI: https://doi.org/10.1016/ S1364-6613(03)00028-7

Monsell, S. (2015). Task set control and task switching. In J. M. Fawcett, E. F. Risko \& A. Kingstone (Eds.), The Handbook of Attention (pp. 139-172). Cambridge, MA: MIT Press.

Monsell, S. (2017). Task set regulation. In T. Egner (Ed.), The Wiley Handbook of Cognitive Control (pp. 29-49). Chichester, West Sussex, UK: John Wiley \& Sons. DOI: https://doi.org/10.1002/9781118920497.ch2

Monsell, S., \& Driver, J. (2000). Banishing the control homunculus. In S. Monsell \& J. Driver (Eds.), Control of cognitive processes: Attention and performance XVIII (pp. 3-32). Cambridge, MA: MIT Press. DOI: https://doi.org/10.7551/mitpress/1481.001.0001

Monsell, S., \& Mizon, G. A. (2006). Can the task-cuing paradigm measure an endogenous task-set reconfiguration process? Journal of Experimental Psychology: Human Perception and Performance, 32, 493-516. DOI: https://doi.org/10.1037/0096-1523.32.3.493

Monsell, S., Sumner, P., \& Waters, H. (2003). Task-set reconfiguration with predictable and unpredictable task switches. Memory \& Cognition, 31, 327-342. DOI: https://doi.org/10.3758/BF03194391

Rogers, R. D., \& Monsell, S. (1995). The costs of a predictable switch between simple cognitive tasks. Journal of Experimental Psychology: General, 124, 207-231. DOI: https://doi.org/10.1037/0096-3445.124.2.207 
Schmidt, J. R., \& Liefooghe, B. (2016). Feature integration and task switching: Diminished switch costs after controlling for stimulus, response, and cue repetitions. Plos One, 11, e0151188. DOI: https://doi. org/10.1371/journal.pone.0151188

Schmidt, J. R., Liefooghe, B., \& De Houwer, J. (2020). An episodic model of task switching effects: erasing the homunculus from memory. Journal of Cognition, 3(1): 22, pp. 1-38. DOI: https://doi.org/10.5334/ joc.97

Schneider, D. W., \& Logan, G. D. (2005). Modeling task switching without switching tasks: A short-term priming account of explicitly-cued performance. Journal of Experimental Psychology: General, 134, 343-367. DOI: https://doi.org/10.1037/0096-3445.134.3.343

Steinhauser, M., Maier, M. E., \& Ernst, B. (2017). Neural correlates of reconfiguration failure reveal the time course of task-set reconfiguration. Neuropsychologia, 106, 100-111. DOI: https://doi.org/10.1016/j. neuropsychologia.2017.09.018

Vandierendonck, A., Liefooghe, B., \& Verbruggen, F. (2010). Task switching: Interplay of reconfiguration and interference control. Psychological Bulletin, 136, 601-626. DOI: https://doi.org/10.1037/a0019791

Verbruggen, F., McLaren, I. P. L., \& Chambers, C. D. (2014). Banishing the control homunculi in studies of action control and behaviour change. Perspectives on Psychological Science, 9, 497-524. DOI: https:// doi.org/10.1177/1745691614526414

Waszak, F., Hommel, B., \& Allport, A. (2003). Task-switching and long-term priming: Role of episodic stimulus-task bindings in task-shift costs. Cognitive Psychology, 46, 361-413. DOI: https://doi.org/10.1016/ S0010-0285(02)00520-0

How to cite this article: Monsell, S., \& McLaren, I. 2020 PEP Does Not Dispense with but Implements Task-Set Reconfiguration. Can It Handle Phenomena More Diagnostic of Endogenous Control? Journal of Cognition, 3(1): 27, pp. 1-5. DOl: https://doi.org/10.5334/joc.109

Submitted: 30 April $2020 \quad$ Accepted: 27 June $2020 \quad$ Published: 10 September 2020

Copyright: ( $) 2020$ The Author(s). This is an open-access article distributed under the terms of the Creative Commons Attribution 4.0 International License (CC-BY 4.0), which permits unrestricted use, distribution, and reproduction in any medium, provided the original author and source are credited. See http://creativecommons.org/ licenses/by/4.0/.

$\mathrm{u}[\mathrm{J}$ Journal of Cognition is a peer-reviewed open access journal published by Ubiquity Press. 